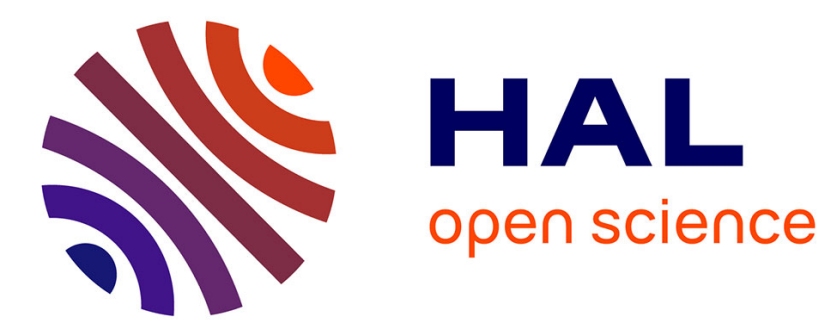

\title{
Computer controlled data acquisition and signal processing for continuous combustion gas sampling
}

Nasser Darabiha, Sebastien Candel, Emile Esposito, Denis Veynante

\section{To cite this version:}

Nasser Darabiha, Sebastien Candel, Emile Esposito, Denis Veynante. Computer controlled data acquisition and signal processing for continuous combustion gas sampling. Revue de Physique Appliquée, 1986, 21 (8), pp.501-508. 10.1051/rphysap:01986002108050100 . jpa-00245467

\section{HAL Id: jpa-00245467 https://hal.science/jpa-00245467}

Submitted on 1 Jan 1986

HAL is a multi-disciplinary open access archive for the deposit and dissemination of scientific research documents, whether they are published or not. The documents may come from teaching and research institutions in France or abroad, or from public or private research centers.
L'archive ouverte pluridisciplinaire HAL, est destinée au dépôt et à la diffusion de documents scientifiques de niveau recherche, publiés ou non, émanant des établissements d'enseignement et de recherche français ou étrangers, des laboratoires publics ou privés. 


\title{
Computer controlled data acquisition and signal processing for continuous combustion gas sampling $\left(^{*}\right)$
}

\author{
N. Darabiha, S. M. Candel $\left({ }^{+}\right)$, E. Esposito and D. Veynante \\ Laboratoire EM2C, CNRS, Ecole Centrale des Arts et Manufactures, 92295 Châtenay-Malabry, France
}

(Reçu le 31 janvier 1986, révisé le 28 avril, accepté le 29 avril 1986)

\begin{abstract}
Résumé. - Cet article concerne le prélèvement de gaz en mode continu. Dans ce mode d'opération, la sonde de prélèvement se déplace en continu à basse vitesse et l'analyse de gaz s'effectue en parallèle. Les déplacements de la sonde ainsi que l'acquisition et le traitement des signaux sont assurés par un ordinateur. Les distorsions associées au mode continu d'opération sont étudiées. Les sources de distorsion considérées sont liées à la réponse d'analyseurs, au temps de transfert dans la ligne de prélèvement, à l'évolution du mélange des gaz prélevés dans la ligne et à la variation du débit massique des gaz prélevés, due à la variation de leur température. Une fonction de transfert du système est ensuite déterminée. L'algorithme utilisé pour restituer le signal d'entrée à partir du signal de sortie est basé sur une méthode d'itération sous contrainte. Des tests et des applications sont ensuite donnés afin de démontrer que la méthode est 'pratique. L'avantage principal de la méthode est qu'elle diminue considérablement le temps d'exploration et ainsi permet une étude détaillée de la structure d'écoulement et de flamme.
\end{abstract}

\begin{abstract}
This paper is concerned with gas sampling in the continuous mode. In this mode of operation the sampling probe is moved at low speed and gas analysis is conducted on line. Probe displacement, data acquisition and signal processing are performed by a computer. Distortions associated with the continuous mode of operation are described. The sources of distorsion considered are related to the analyser response function, the sampling line time lag, the mixture evolution of the sampled gases in the line, and the variation of the mass flow in the line due to temperature changes of the sampled gases. A system transfer function is then determined. The algorithm used to restore the input signal from the output signal is based on a constrained iteration method. Tests and applications are given to prove that the method is practical. The main advantage of the method is that it considerably reduces the exploration time and allows detailed studies of flow and flame structures.
\end{abstract}

\section{Introduction.}

Considerable progress has been made in the development of new optical methods for combustion diagnostics (see Bechtel and Chraplyvy [1] and Boyer [2] for recent reviews). Yet most of these new techniques are not simple to use in the study of practical combustors. Thus gas sampling and analysis remain valuable for the determination of mean local concentrations in many small and large scale applications. However, many problems are associated with gas sampling. First, the method is intrusive and the sampling probe perturbs the flow field. Second, the precision of the concentration measurements is strongly dependent upon the possibility of freezing the

$\left(^{*}\right)$ A preliminary version of this study was presented at the 9th Icoders, Poitiers, France.

$\left(^{+}\right)$Also with ONERA, 92322 Châtillon, France. chemical reactions in the probe. This is usually achieved by aerodynamic quenching and cooling of the sampled gases but a very careful design of the probe is required. An extensive literature deals with these problems. Detailed discussions of these aspects are due to Tine [3], Chedaille and Braud [4], Bilger [5], Bowman [6] and Gouldin [7]. A critical analysis of the internal aerodynamics of sampling probes is due to Colket [8]. Lengelle and Verdier [9] give a complete review of the basic techniques, typical applications and recommended practices.

Up to now, gas sampling has been mostly used in step by step measurements. The probe samples the combustion gases at a fixed point until a stabilised value is obtained from gas analysers after a time delay corresponding to the sum of the transit time in the line $\tau_{\mathrm{T}}$ and the response time of the gas analyser $\tau_{\mathrm{A}}$. Typically $40 \mathrm{~s}$ are required for each point. This long sampling time restricts measurements to a few field 
points and does not allow detailed explorations of the flame structure except for very simple configurations.

Therefore it is tempting to use gas sampling in a continuous mode by moving the sampling probe at low speed and performing on-line gas analysis. The method is attractive because it is much faster (by a factor of 10 to 100) than the classical step-by-step procedure. However it poses some unexpected problems and requires an application of signal restoration algorithms.

Section 2 describes the sampling equipment, displacement and data acquisition systems. The various distortions associated with the continuous mode of operation are discussed in section 3 and the global distorsion function of the system is identified. A signal restoration algorithm is then presented in section 4 . Finally, tests and typical experimental applications are presented in section 5 .

\section{Experimental configuration, gas sampling system and data acquisition.}

The experimental configuration is displayed in figure 1 . A mixture of air and propane is injected through a long duct into a dump combustor. The combustor has a square cross section of $100 \times 100 \mathrm{~mm}^{2}$ and it is $200 \mathrm{~mm}$ long (Fig. 2). The injection plane comprises five narrow rectangular slots separated by four

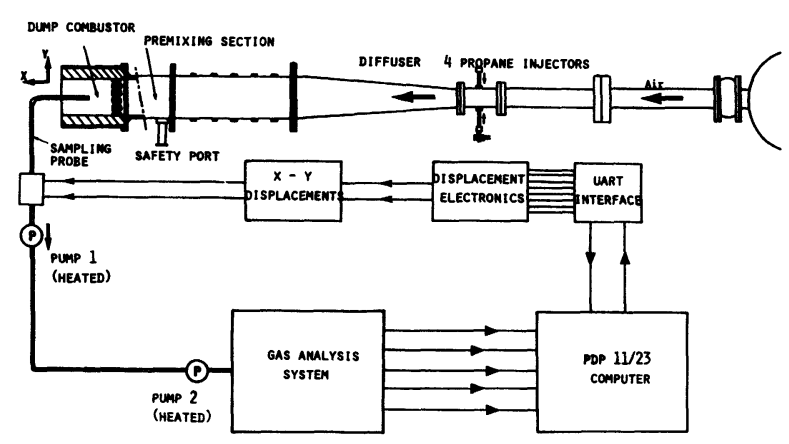

Fig. 1. - General set up of the test rig.

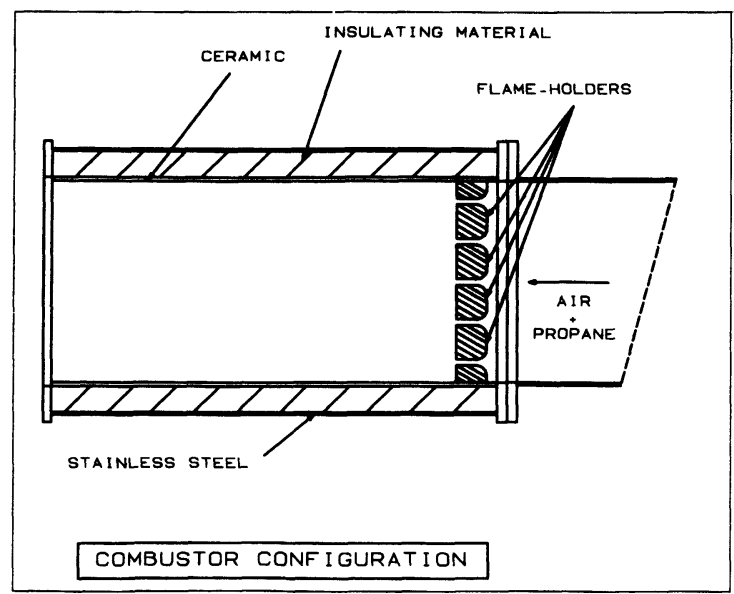

Fig. 2. - The combustion chamber. backward-facing steps. Two half steps separate the first and last slots from the lateral walls. Each slot has a rectangular cross section of $3 \times 100 \mathrm{~mm}^{2}$ and the blockage is $85 \%$. The combustor walls are made of ceramic and they are surrounded by a layer of insulating material. A stainless steel structure holds the different parts together. Further details on the combustion facility may be found in Grouset et al. [10].

The sampling probe is water-cooled. It has a $1 \mathrm{~mm}$ diameter throat connected to an inner tube of $2 \mathrm{~mm}$ in diameter (Fig. 3). A first pump is placed directly behind the probe to assure a pressure drop corresponding to sonic conditions at the throat. A second pump operates at the other end of a $4 \mathrm{~mm}$ diameter sampling line. The gas is then analysed with infrared absorption detectors (COSMA RUBIS 3000) for $\mathrm{CO}$ and $\mathrm{CO}_{2}$, paramagnetic analyser (COSMA RUBIS 3000) for $\mathrm{O}_{2}$, chemiluminescent detector (Beckmann 951) for $\mathrm{NO}_{x}$ and a flame ionization detector for unburned hydrocarbons UHC (IPM RS5). The analysers output signals are transmitted in analog form to a PDP 11/23 computer equiped with a 12 bit, 8 differential channel analog to digital converter. The raw data are then conditioned and stored as a file on a disk. This file is then retrieved and processed for signal calibration, restoration and display.

The computer controls the probe displacement and velocity in two perpendicular dimensions. The exploration plane is set at the beginning of the experiment. In a given experiment, the probe velocity during data acquisition is adapted to the flame structure under exploration. For the experimental configuration described above the velocity is typically between 0.5 and $1 \mathrm{~mm} / \mathrm{s}$. The sampling frequency being from 5 to 10 points per second, the spatial sampling period is then between 0.1 and $0.2 \mathrm{~mm}$. A complete exploration of an $80 \times 200 \mathrm{~mm}$ combustor plane with 20 vertical traverses at a probe velocity of $1 \mathrm{~mm} / \mathrm{s}$ and a sampling frequency of $10 \mathrm{~Hz}$ takes approximately $40 \mathrm{mn}$ to store 16000 data samples. In comparison, a step-bystep measurement would only allow an acquisition of approximately 60 data samples in the same period of time.

\section{Distortions associated with the continuous mode of operation.}

Only distortions specific to the continuous mode of operation will be considered. The other distortions associated with probe sampling are extensively discussed in the literature cited in the introduction.

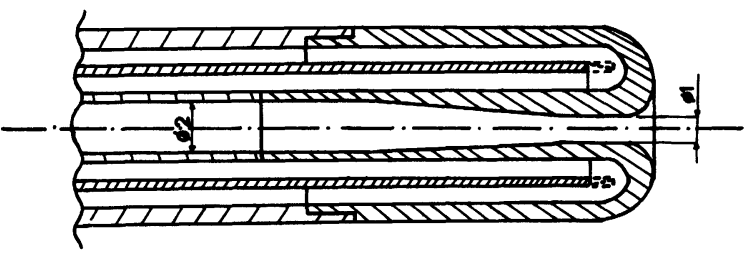

Fig. 3. - Details of the sonic probe inlet. 
The sources of distortions that we shall consider are related to :

(1) the analyser response function;

(2) the sampling line time lag;

(3) the mixture evolution of the sampled gases in the line;

(4) the variation of mass flow rate in the line due to temperature changes of the sampled gases.

These perturbations successively modify the information as shown in figure 4 . The input to the system is the mole fraction $X$ and the distorted output signal is $S$. The signal processing problem then consists of first identifying the transfer function of the system and then restoring the input $X$ from the output signal $S$.

To begin let us consider the analyser dynamics. It is known and also well verified experimentally that input and output $(Y$ and $S$ ) of standard analysers are related by the first order differential equation

$$
Y=S+\tau_{\mathrm{A}} \frac{\mathrm{d} S}{\mathrm{~d} t}
$$

where $\tau_{\mathrm{A}}$ is a time constant characteristic of the equipment. Now the probe is moved with a vertical speed $v=\mathrm{d} y / \mathrm{d} t$ and hence one can write

$$
Y=S+\left(\tau_{\mathrm{A}} v\right) \frac{\mathrm{d} S}{\mathrm{~d} y} .
$$

Clearly the product $\tau_{\mathrm{A}} v$ (for all analyses) must be sufficiently small if the output $S$ is to resemble the input $Y$. This condition sets an upper limit to the probe displacement velocity $v$. If $l$ is a characteristic length scale of the mole fraction field then $v$ must be less than $l / \tau_{\mathrm{A}}$. For example if $l=1 \mathrm{~mm}$ and $\tau_{\mathbf{A}} \simeq 1 \mathrm{~s}$ the probe should be moved at a speed lower than $1 \mathrm{~mm} / \mathrm{s}$.

Next consider the sampling line (i.e. the pipe connecting the probe to the analysers). This line is usually a few meters long and it introduces a time delay $\tau_{\mathrm{T}}$ between its input and output. The measurement of this delay may be performed by placing the probe in the vicinity of a steep concentration gradient. The probe is then set in motion and data acquisition is started simultaneously. The minimum delay time is then determined as that corresponding to the first analyser signal variation. This measurement includes the analyser time constant which is usually small compared to the line transit time $\tau_{\mathrm{T}}$. Typically $\tau_{\mathrm{T}}$ is of the order of $10 \mathrm{~s}$. We next consider the third source of distortion related to the mixture evolution in the sampling line. To illustrate this aspect let us consider

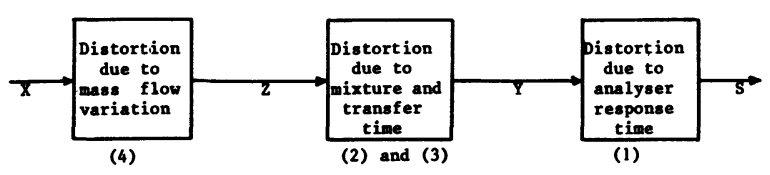

Fig. 4. - Signal distortion block-diagram. the following experiment. The sampling probe is placed outside and in the near vicinity of the combustor exit plane. It scans a vertical line in the symmetry plane of the combustor. In that region the $\mathrm{CO}_{2}$ concentration is uniform except near the walls where it decreases rapidly. If one performs two continuous samplings by moving the probe upwards and then downwards on the same line the results obtained do not coincide but are symmetric of each other (see Fig. 5). This behaviour is caused by mixing of the sampled gases in the transfer line. In fact the flow in the line is laminar $(R e<1000)$, a Poiseuille velocity profile is established in the cylindrical pipe and as a consequence a concentration gradient develops in the radial direction. Thus radial diffusion becomes important. Mixing also occurs due to axial diffusion and line singularities such as bends, pumps and valves. Consequently positive concentration gradients sampled by the probe are smoothed out while negative gradients are steepened.

A detailed analysis of this mixing problem is not feasible but the phenomenon may be represented by an empirical integro-differential equation. This model equation is based on simple ideas :(1) it must represent cumulative and delay effects (2) experimental evidence indicates that the derivative of the input signal must appear explicitely. One possible model is :

$$
\begin{array}{r}
Y(t)=Z(0)+\int_{0}^{t-\tau_{\mathrm{T}}} \frac{\mathrm{d} Z}{\mathrm{~d} \tau}(\tau)[1-h(t-\tau)] \mathrm{d} \tau, \\
t>\tau_{\mathrm{T}}
\end{array}
$$

and $Y(t)=Z(0)$ for $t \leqslant \tau_{\mathrm{T}}$.

In this equation $Z(t)$ is the mole fraction at the probe exit (i.e. beyond the probe throat), $Y(t)$ represents that value at the tranfer line exit just before the analyser and $h(t)$ is a kernel characterizing the mixing

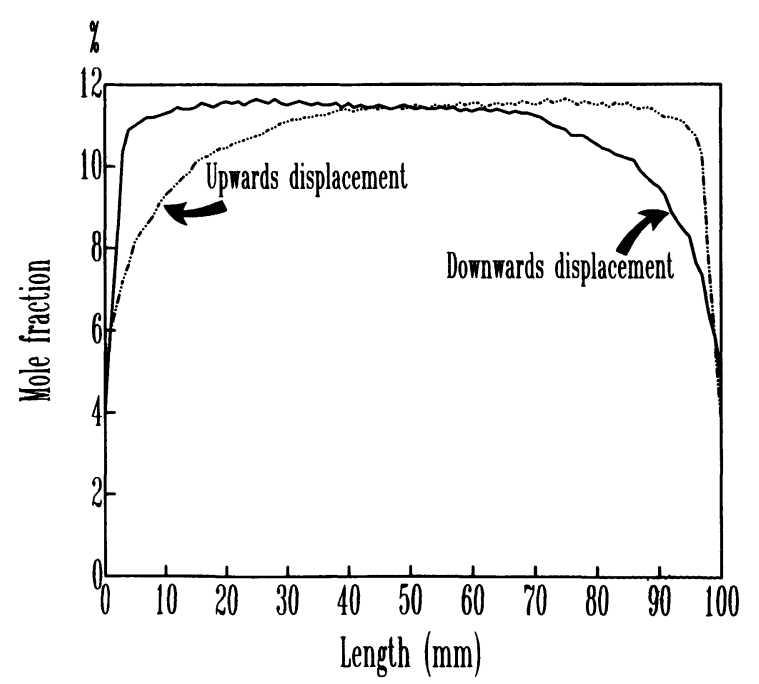

Fig. 5. $-\mathrm{CO}_{2}$ mole fraction profiles at chamber exit for upwards and downwards sampling probe displacements on the same line. 
and transfer process. It is rather natural to take an exponential function for this kernel however a better choice is

$$
h(t)=\exp \left[-\alpha\left(t-\tau_{\mathrm{T}}\right)\right] \exp \left[-\beta\left(t-\tau_{\mathrm{T}}\right)^{2}\right]
$$

for $t>\tau_{\mathrm{T}}$ and $h(t)=1$ for $t \leqslant \tau_{\mathrm{T}}$ where $\alpha$ and $\beta$ are equipment dependent empirical coefficients. These coefficients are adjusted by tests performed with step and square pulse input functions (typical values of these parameters are $0.4,0.04$ ).

The fourth source of distortion is associated with the mass flow rate changes as a function of temperature. In most permanent combustors the static pressure is nearly constant while the gas temperature varies in a wide range (between the fresh mixture temperature and the hot combustion products temperature). As a consequence the mass flow rate entering the probe is more important in regions of low temperature and diminishes in hot regions. As the sampled gases are cooled and brought to a constant temperature low temperature gases occupy a greater portion of the transfer line and take longer to be evacuated from the system. Now the analyser output is sampled at a constant rate, the sampling period being $\Delta t$. The samples obtained however correspond to a nonuniform rate at the probe entrance and the sampling period $\delta t$ of the input $X$ is a function of temperature. The following function may be used to reflect this nonuniformity

$$
\delta t=\Delta t\left[\frac{T(t)}{T\left(t-\tau_{\mathrm{T}}\right)}\right]^{k}
$$

where $k$ is a constant greater than $1 / 2$ and less than 1 . Clearly the mass flow rate variations described here cause a change in the time scale of the input signal.

Returning to the block diagram of figure 4 it appears that the last block corresponding to the analyser response function is easily resolved numerically. The first block corresponds to a change in time scale and it is also quite simple. The second block is however more complex and is to be treated more carefully.

Consider again expression (3) which describes this second block. In discrete form this equation becomes

$$
\begin{gathered}
T_{k}=Z_{0} \text { for } k=0 \text { to } N \\
Y_{i+N}=Z_{0}+\sum_{j=0}^{i}\left(Z_{j+1}-Z_{j-1}\right) h_{N+i-j}
\end{gathered}
$$

where $N=\tau_{\mathrm{T}} / \Delta t, i=\left(t-\tau_{\mathrm{T}}\right) / \Delta t$ and $j$ is a discrete time index taking values from 0 to $i$.

The previous expressions may be written in more compact form as

$$
Y=D Z
$$

where $Z$ and $Y$ are respectively input and output vectors and $D$ is a distortion matrix.

\section{Signal restoration algorithm.}

In this section we only consider the second block in the diagram of figure 4 . In the previous section we identified the distortion function for this block. If $Z$ designates the unknown input signal and $Y$ is the known output signal, we have just shown that the equation :

$$
Y=D Z
$$

provides a suitable representation of that block. Now we wish to recover $Z$ given $Y$ and $D$. In principle $Z$ might be obtained by inverting the distortion operator $D$ such that :

$$
Z=D^{-1} Y \text {. }
$$

However this is not possible in general. In fact, as indicated in the previous section the matrix operator $D$ is not well known. And, even if it is known, its determinant is generally very small. Therefore, classical inversion methods or even those based on least mean squares cannot be used to obtain the solution. Furthermore, we have some a priori information on certain properties of the input signal and this knowledge may be useful in obtaining a proper solution of equation (7). Therefore it is more adequate to restore the input signal with an alternative method. One technique which has been extensively used in the signal processing literature is based on the method of successive approximations (see Schafer et al. [11] for a detailed review of this technique). In this method the signal $Z$ is deduced from the iteration equation

$$
Z^{(k+1)}=F Z^{(k)}
$$

where $F$ is an operator constructed from (7) and incorporating some of the constraints which characterize the input signal $Z$. One convenient way of expressing the a priori information on signal $Z$ is to define a constraint operator $C$ such that

$$
Z=C Z \text {. }
$$

Here we know that the concentration has only positive values and the constraint operator may be the positivity operator such that

$$
C Z=\left\{\begin{array}{ll}
Z & \text { if } Z \geqslant 0 \\
0 & \text { otherwise }
\end{array} .\right.
$$

Then it is also possible to write expression (7) in the form

$$
Y=D C Z
$$

and an iteration equation may be constructed from a linear combination of (9) and (10)

$$
Z=C Z+\lambda(Y-D C Z)
$$

where $\lambda$ is a relaxation parameter constant depending on the signal $Z$. Now the previous identity is easily 
transformed into an iteration

$$
Z^{(k+1)}=C Z^{(k)}+\lambda\left(Y-D C Z^{(k)}\right)
$$

and the corresponding constrained iteration operator is in this case such that

$$
F Z=\lambda Y+(I-\lambda D) C Z .
$$

A recommended initial guess for starting the iteration is $Z_{0}=\lambda Y$ or $Z_{0}=Y$.

Convergence of iteration (12) is guaranteed if the operator $F$ is a contraction mapping. We did not rigorously establish this property, but rapid convergence was obtained in all of our applications. About 7 iterations were needed in most cases. This rapid convergence may be considered to provide an $a$ posteriori justification to the method.

\section{Results and applications.}

Before applying the restoration method discussed above to complete explorations of our combustor, we shall first give several tests illustrating the distortion problem.

The first test is performed to obtain the response of the system to a concentration step (curve (a) in Fig. 6). Indeed it is essential to first identify the system response function before trying to restore the concentration signal. The step input is obtained by passing the probe through a steep concentration gradient (for example at a close distance from the inlet plane). Curve $b$ in figure 6 represents the measured system response. The calculated system response is represented by curve $c$ in figure 6 and it nearly coincides with the measured response, thus showing that the system response to a step has been suitably identified.

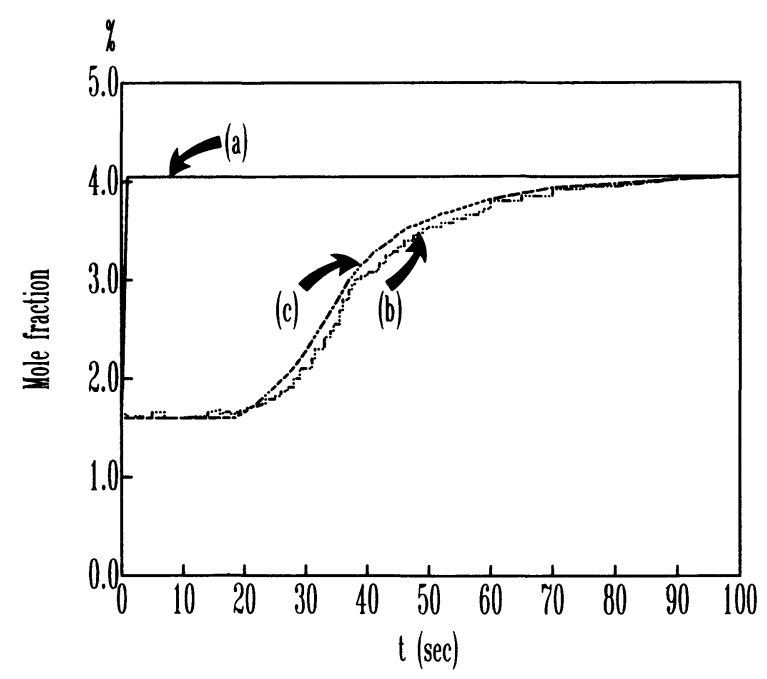

Fig. 6. - System response to a concentration step; a) original step; b) system response, and c) calculated system response.
We next apply the iterative restoration method to the upwards-downwards experiment described in section 3 (see Fig. 5). The result is now quite satisfactory (Fig. 7) as the two curves obtained by iterative inversion method now coincide.

The third test is to examine the restoration capability of the algorithm for the difficult case of a narrow rectangular concentration pulse. Curve (a) in figure 8 corresponds to the input concentration obtained by step-by-step measurements. Curve (b) in figure 8 represents the distorted analyser output, while curve (c) is the restored concentration obtained by the iterative method. The minimum value of the input concentration is correctly retrieved and the position of the rectangular concentration pulse is well estimated.

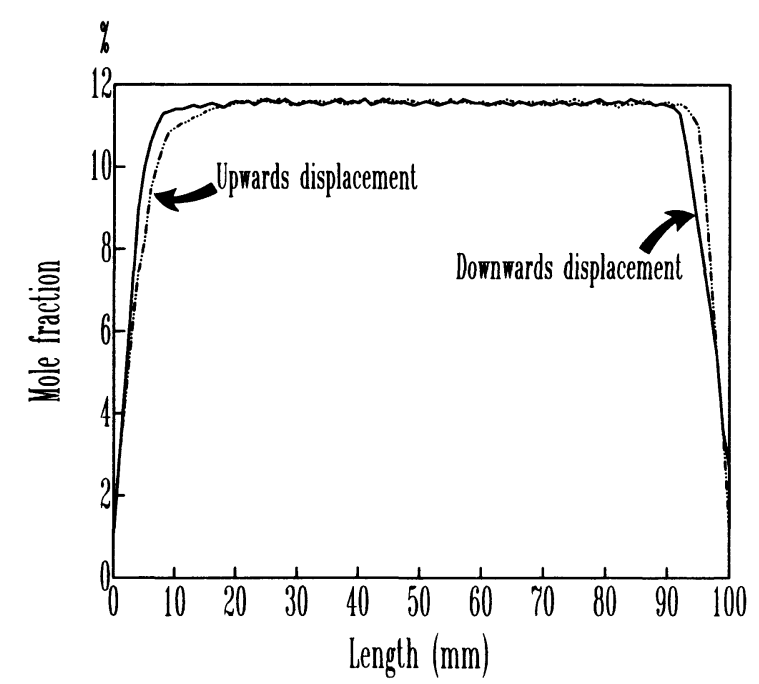

Fig. 7. - Restored $\mathrm{CO}_{2}$ mole fraction profiles at chamber exit for upwards and downwards sampling probe displacements, obtained from original curves on figure 5 by applying the iterative method.

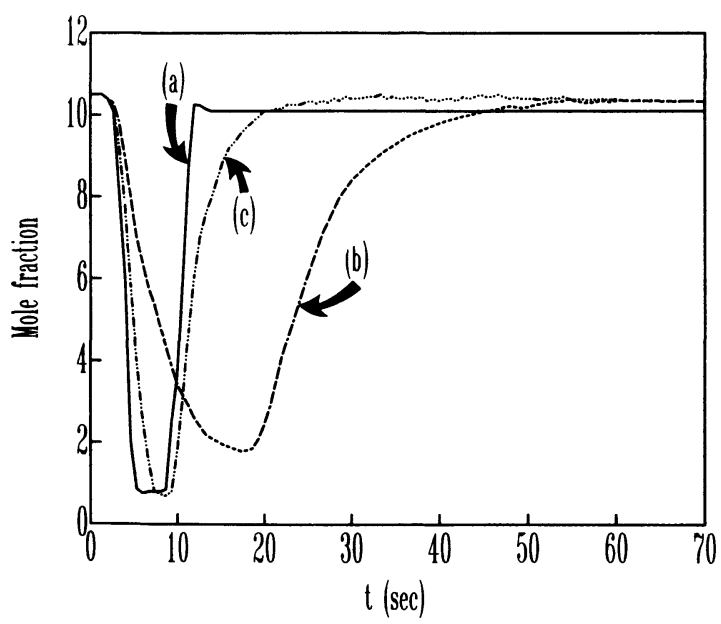

Fig. 8. - System response to a rectangular mole fraction pulse; a) original mole fraction variation; b) system response and c) calculated variation. 
The restored mole fraction is not as sharp as the input mole fraction but the result is nevertheless satisfactory for most purposes.

To show the power of the method, we now consider an application to the turbulent combustor described in section 2. To obtain the structure of the flame zone the gas sampling probe is moved in the vertical central plane of the combustor cavity and it scans a domain of 80 by $200 \mathrm{~mm}^{2}$. The vertical displacement of the probe is continuous $(0.5 \mathrm{~mm} / \mathrm{s})$ and step-by-step in the horizontal direction. Figures 9 and 10 respectively display the $\mathrm{CO}_{2}$ and $\mathrm{CO}$ mole fraction distributions corresponding to an airflow rate of $87.2 \mathrm{~g} / \mathrm{s}$ ) and an equivalence ratio of 0.747 (defined as the fuel-air ratio divided by the stoichiometric fuel-air ratio). Results are displayed as three-dimensional views and contour plots of the mode fraction distribution.

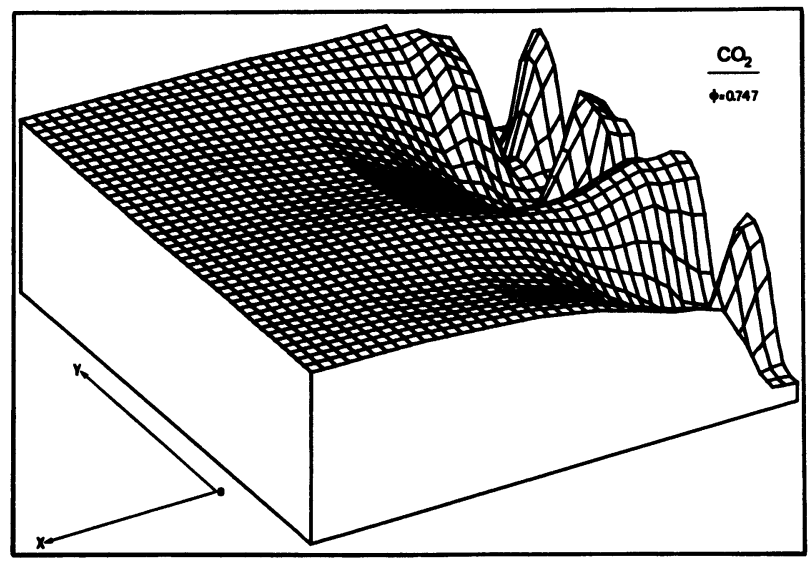

(a)
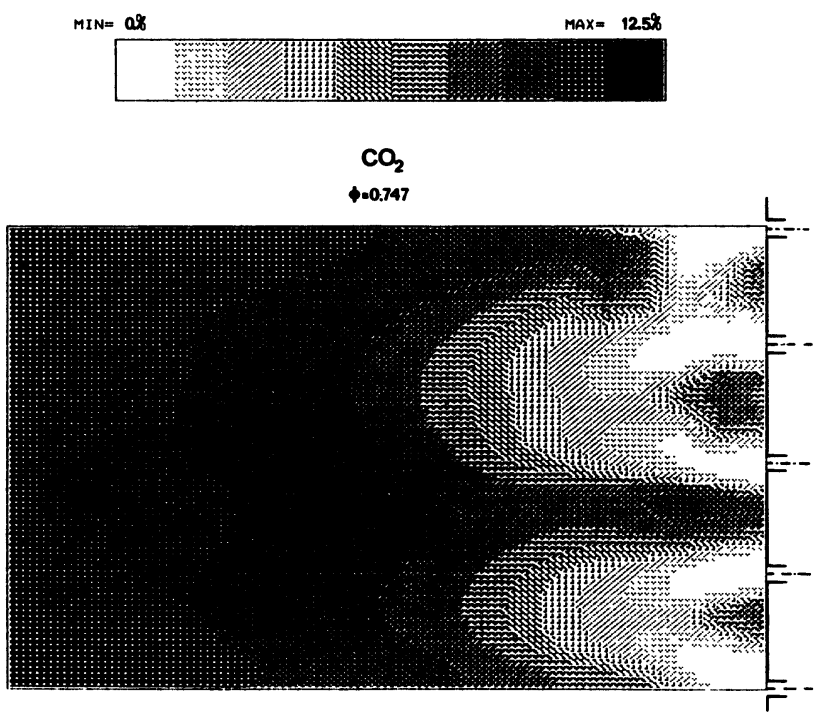

(b)

Fig. 9. $-\mathrm{CO}_{2}$ concentration map in the combustor; airflow rate $=87.2 \mathrm{~g} / \mathrm{s}$ and equivalence ratio $=74.7 \%$; a) three dimensional view of the mole fraction distribution; $b$ ) contour plot of the mole fraction distribution on a linear scale of grey. The scale is defined in the upper part of the plot.
The contour plots are drawn on a linear scale of ten grey levels. As an example, to obtain quantitative information from figure $9 \mathrm{~b}$ one may use the scale of symbols defined in the upper portion of the plot. The jets of fresh propane-air mixture appear clearly behind each inlet. In the vicinity of each step $\mathrm{CO}_{2}$ increases indicating the presence of recirculating burnt gases. This recirculation zone initiates the combustion of the fresh mixture and stabilises the flame. At about $3 \mathrm{~cm}$ from the inlet plane the two lower jets interact and combine. The two inner jets form another merged jet while the upper jet remains isolated.

The maximum ( $0.4 \%)$ CO mole fraction (Fig. 10) appears in the reaction zone and it disappears at the combustor exit, where the $\mathrm{CO}_{2}$ mole fraction is at its maximum. The $\mathrm{CO}$ mole fraction also vanishes in the recirculating zones while it increases in the mixing layers separating the fresh mixture and burnt gases.

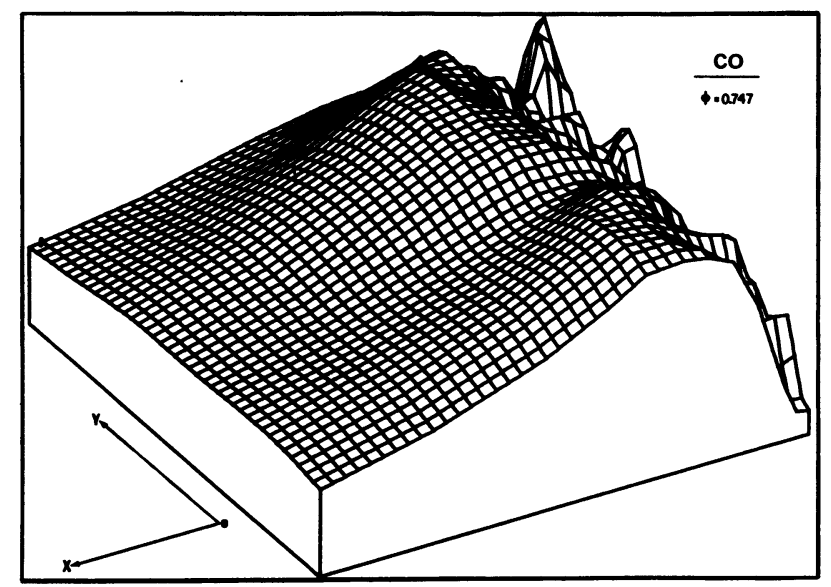

(a)
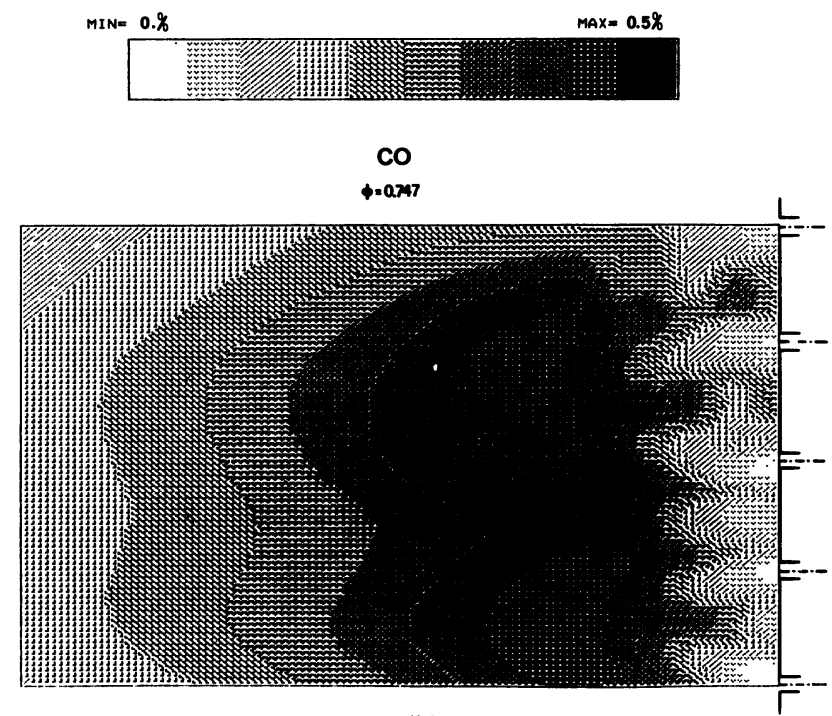

(b)

Fig. 10. - CO concentration map in the combustor; airflow rate $=87.2 \mathrm{~g} / \mathrm{s}$ and equivalence ratio $=74.7 \%$; a) three dimensional view of the mole fraction distribution; b) contour plot of the mole fraction distribution on a linear scale of grey. The scale is defined in the upper part of the plot. 
Figures 11 and 12 respectively show the distribution of $\mathrm{CO}_{2}$ and $\mathrm{CO}$ mole fractions corresponding to another set of operating conditions $\left(m_{\text {air }}=74 \mathrm{~g} / \mathrm{s}\right.$, $\phi=0.878$ ). The five jets are now separated and the flow is periodic in space. The reactive zone is more compact here. A big region of high $\mathrm{CO}$ mole fraction (Fig. 12) is observed and it is closer to the inlet plane than in figure 10. The maximum $\mathrm{CO}$ mole fraction $(0.5 \%)$ is larger than in figure $10(0.4 \%)$.

Systematic investigations indicate that there are many possible flow and flame structures corresponding to stable and unstable regimes depending on mass flow-rate and equivalence ratio. A discussion of this aspect is given in Darabiha et al. [12]. Further examples of application are also contained in Darabiha [13].

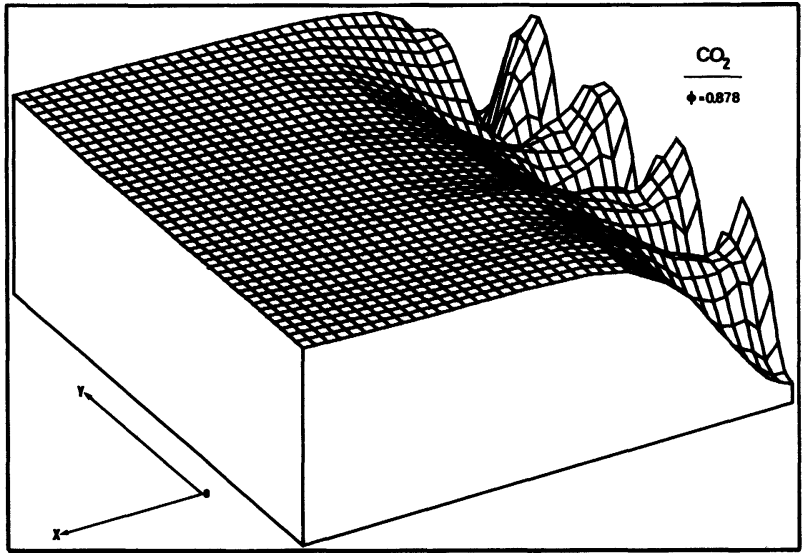

(a)
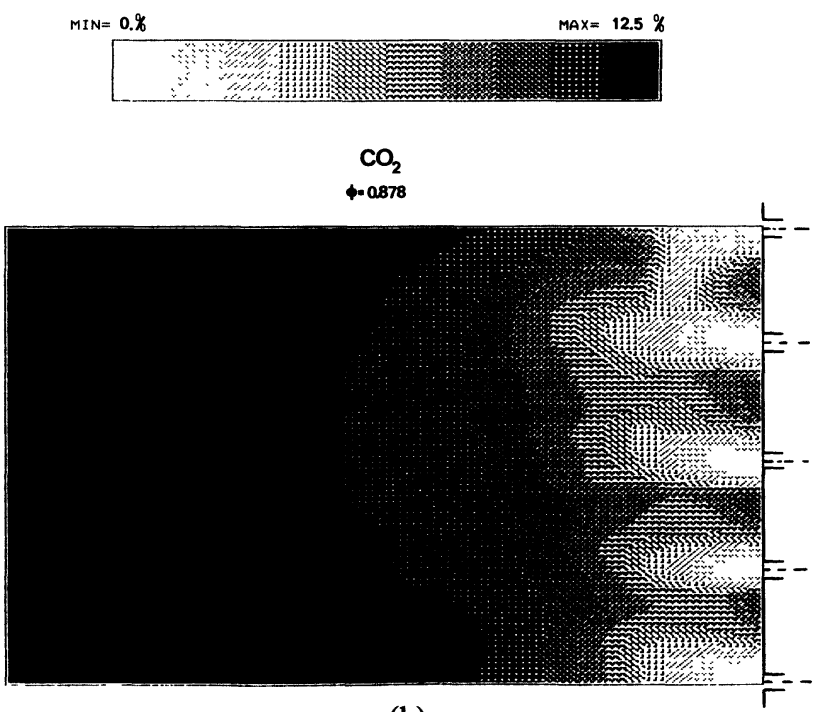

(b)

Fig. 11. - $\mathrm{CO}_{2}$ concentration map in the combustor; airflow rate $=74 \mathrm{~g} / \mathrm{s}$ and equivalence ratio $=87.8 \%$; a) three dimensional view of the mole fraction distribution; b) contour plot of the mole fraction distribution on a linear scale of grey. The scale is defined in the upper part of the plot.

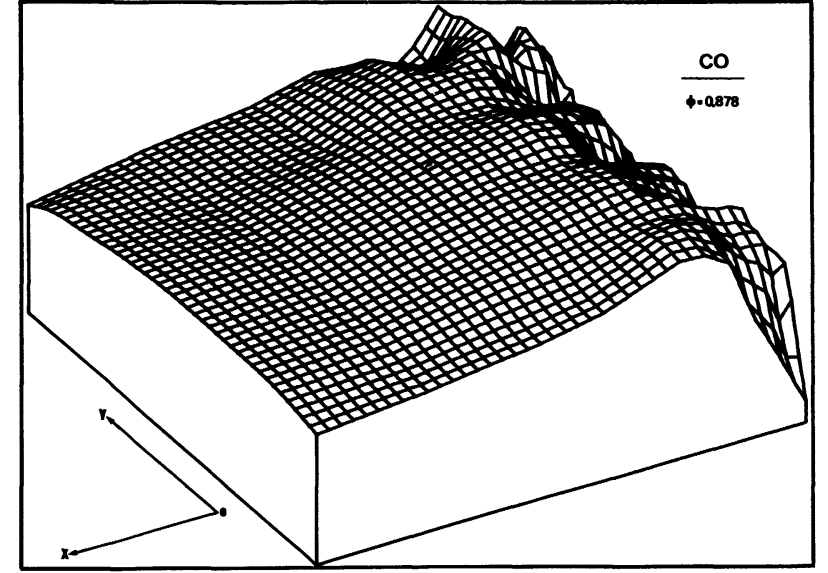

(a)

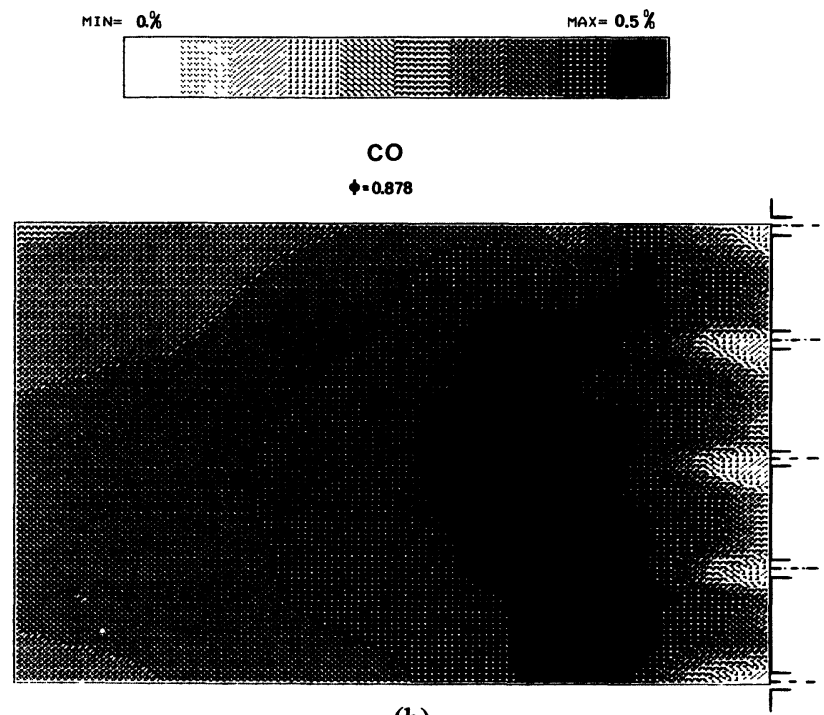

(b)

Fig. 12. - CO concentration map in the combustor; airflow rate $=74 \mathrm{~g} / \mathrm{s}$ and equivalence ratio $=87.8 \%$; a) three dimensional view of the mole fraction distribution; b) contour plot of the mole fraction distribution on a linear scale of grey. The scale is defined in the upper part of the plot.

\section{Conclusion.}

Up to now gas sampling has been mostly used in stepby-step measurements. As detailed explorations require excessive testing times, that mode of gas sampling would restrict measurements to a few field points. The continuous computer controlled sampling mode presented in this paper considerably reduces the exploration time but induces several problems such as analyser response time, gas mixing in the transfer line and flow rate variation in that line due to temperature. These problems are solved successfully by identifying a system transfer function and using an iterative restoration method. This mode of gas sampling allows detailed studies of flow and flame structures and it is a useful tool in combustion experiments. 


\section{Acknowledgments.}

Financial support provided by the Société Nationale d'Etude et de Construction de Moteurs d'Aviation (SNECMA) and by a CNRS ATP is gratefully acknow- ledged. Bruno Romier as a graduate student took an important part in the development of this work. Data display and graphics were performed on an IBM 4341 computer made available to us by the IBM Co.
[1] Betchel, J. H. and Charplyvy, A. R., Laser diagnostics of flames, combustion, products and sprays. Proc. IEEE 70 (1982) 658-677.

[2] BOYER, L., Optical diagnostics in flows applicationexperiments in combustion. Nato advanced study institute series, Ed. Velarde M.G. (Plenum Press) 1983.

[3] TINE, G., Gas sampling and chemical analysis in combustion processes (Pergamon Press, New York) 1961.

[4] Chedaille, J. and Braud, Y., Measurements in flames (E. Arnold, London) 1972, p. 94.

[5] Bilger, R. W., Probe measurements in turbulent combustion. Experimental diagnostics in gas phase combustion systems. Progr. Astronaut. Aeronaut. 53 (1977) 49.

[6] Bowman, C. T., Probe measurements in flames. Experimental diagnostics in gas phase combustion systems. Progr. Astronaut. Aeronaut. 53 (1977) 3.

[7] Gouldin, F. C., Probe measurements in multidimensional reacting flows. Testing and measurement techniques in heat transfer and combustion. Agard CP 281 (1980).

[8] Colket, M. B., Chiapetta, L., Guile, R. N., ZABielski,
M. F. and SEERY, D. J., Measurements, diagnostics, internal aerodynamics of gas sampling probes. Comb. Flame 44 (1982) 3-14.

[9] Lengelle, G. and Verdier, C., Gas sampling and analysis in combustion phenomena. Agard AG 168 (1973).

[10] Grouset, D., Esposito, E. and Candel, S. M., Model of the recirculating flow in a premixed combustor. Combustion in reactive systems. Progr. Astronaut. Aeronaut. 76 (1981) 360.

[11] Schafer, R. W., Mersereau, R. M. and Richards, M. A., Constrained iterative restoration algorithms, Proc. IEEE 69, № 4 (1981) 432.

[12] Darabiha, N., Poinsot, T., Candel, S. M. and EsPosito, E., A correlation between flame structure and acoustic instabilities. Presented at the 10th ICDERS, Berkeley, California August 4-9 1985. Accepted for publication in Progr. Astronaut. Aeronaut., (1985).

[13] Darabiha, N., Un modèle de flamme cohérente pour la combustion prémélangée : analyse d'un foyer turbulent à élargissement brusque. Doctoral Thesis, Ecole Centrale des Arts et Manufactures, Châtenay-Malabry, France (1984). 